\title{
稠杂环化合物在红色磷光铱配合物中的应用
}

\author{
王玲霞 梅群波 ${ }^{*}$ 颜 芳田 波翁洁娜张涁黄 维
}

(有机电子与信息显示国家重点实验室培育基地, 南京邮电大学信息材料与纳米技术研究院, 南京 210046)

\begin{abstract}
摘要: 在过去的几十年里, 有机发光二极管(OLED)由于潜在的优势, 在全彩显示领域引起了高度重视. 电致 磷光材料因其优异的发光性能, 引起了人们广泛关注. 对于实际应用的平板显示器, 蓝、绿、红三基色是必不可 少的. 相对于高效的绿光材料, 红光磷光材料仍然存在色纯度差、效率低和亮度不足等问题, 因此设计合适的红 光材料成为具有挑战性的问题. 稠杂环化合物因发光量子效率高、发光颜色可调、平衡电荷注入及迁移等优越 性能而广泛应用于红色磷光铱配合物. 本文综述了近几年稠杂环化合物在小分子、树枝状及高分子红色磷光铱 配合物中的应用, 阐述了铱配合物分子结构对材料光电性质及器件性能的影响, 最后展望了稠杂环化合物在红 光磷光材料中的应用前景.
\end{abstract}

关键词： 磷光材料; 铱配合物; 稠杂环化合物； 树枝状分子； 高分子

中图分类号: 0644

\section{Application of Fused-Heterocyclic Compounds in Red Phosphorescent Iridium(III) Complexes}

\author{
WANG Ling-Xia MEI Qun-Bo* YAN Fang TIAN Bo WENG Jie-Na \\ ZHANG Bin HUANG Wei* \\ (Key Laboratory for Organic Electronic \& Information Displays, Institute of Advanced Materials, \\ Nanjing University of Posts \& Telecommunications, Nanjing 210046, P. R. China)
}

\begin{abstract}
Organic light-emitting diodes (OLEDs) have attracted considerable attention during the last decade because of the potential advantages associated with their usage in full-color displays. Electroluminescent phosphorescent materials have also enjoyed similar levels of attention because of their excellent luminescent properties. The three primary colors, blue, green, and red, are essential for the practical application of phosphorescent complexes in flat-panel displays. Relative to the efficient green phosphorescent materials, red phosphorescent materials suffer many problems, including poor color purity, low efficiency, and low luminance, and the design of appropriate red colored materials therefore represents a significant challenge. Fused-heterocyclic compounds have been widely used in red phosphorescent iridium(III) complexes because of their high quantum efficiency, color adjustability, and balanced charge injection and migration. This review summarizes the development and application of fused-heterocyclic compounds in recent years in small molecule, dendrimer and polymeric red phosphorescent iridium(III) complexes. The influence of the molecular structures of iridium(III) complexes on the optical and electrical properties and device performances has also been described. Finally, a discussion of the prospect of developing fused-heterocyclic compounds in the red phosphorescent materials has also been provided.
\end{abstract}

Received: March 12, 2012; Revised: May 2, 2012; Published on Web: May 4, 2012.

"Corresponding authors. MEI Qun-Bo, Email: iamqbmei@njupt.edu.cn. HUANG Wei, Email: iamwhuang@njupt.edu.cn; Tel: +86-25-85866396. The project was supported by the National Key Basic Research Program of China (973) (2009CB930601), National Natural Science Foundation of China (50803027, 50903001, 20905038), and Natural Science Fund for Colleges and Universities in Jiangsu Province, China (08KJD430020). 国家重点基础研究发展规划项目(973) (2009CB930601), 国家自然科学基金(50803027, 50903001, 20905038)及江苏省高校自然科学基础研究 面上项目(08KJD430020)资助

(C) Editorial office of Acta Physico-Chimica Sinica 
Key Words: Phosphorescent material; Iridium(III) complexes; Fused-heterocyclic compound; Dendrimer; Polymer

\section{1 引言}

有机金属配合物发光材料是继无机发光材料 之后发展起来的新型交叉研究领域, 与无机发光材 料相比, 有机金属配合物发光材料具有发光效率 高、亮度大、视角宽、响应速度快等优点. 其中具有 $d^{6}$ 和 $d^{8}$ 电子结构的铱 $(\mathrm{Ir})$ 、铂 $(\mathrm{Pt})$ 、锇 $(\mathrm{Os})$ 等重金属配合 物, 由于能够产生强烈的自旋-轨道耦合, 增大了单 重态-三重态的系间窝跃几率, 较大程度地提高了磷 光效率, 缩短了磷光寿命, 减少了磷光淬灭, 实现了 室温下的磷光发射, 而受到国内外众多研究学者的 青睐. ${ }^{1-3}$ 在众多过渡金属有机配合物中, 以铱为内核 的电致磷光材料因具有相对较短的三重态寿命和 较高的发光亮度, 已成为近几年研究的热点. ${ }^{4}$ 通过 修饰改变配体的种类和结构可以得到不同性能、发 光颜色的磷光材料, 获得高效率的红、绿、蓝三基色 器件. 目前, 绿光磷光材料是发展最成熟的一类材 料. ${ }^{5}$ 而红光、蓝光材料由于分别受限其较小的能隙 和主体材料不匹配等因素, 发展势头远远落后于 绿光材料. 已知的性能较优的红光磷光材料包括 (btp) $)_{2} \operatorname{Ir}(\mathrm{acac}$ )和(piq) $2 \operatorname{Ir}(\mathrm{acac})$ (btp: 2-(2'-苯并噻吩基) 吡啶- $N, C 3^{\prime}$, acac: 乙酰丙酮, piq: 1-苯基异喹啉). 红 色发光材料的研究成为制约高质量信息显示发展 的瓶颈. 造成这种状况的主要原因是: (1) 对应于红 光发射的化合物能级差较小, 这为红光材料配体的 设计增加了困难; (2) 红光材料体系中, 存在较强的 $\pi-\pi$ 键相互作用, 或者具有强的电荷转移特性, 都会 加剧分子的聚集, 易导致淬灭现象; (3) 红光材料稳 定性较低. 因此选择合适的红光材料, 通过降低能 隙 $\left(E_{\mathrm{g}}\right)$, 从而降低跃迁需要的能量, 发生红移. 降低 能隙一般有三种方法: 通过增加分子的刚性, 如增 大共平面性, 使电子跃迁的能量降低; 通过增大芳 环上 $\pi$ 共轭链长度, 从而降低电子跃迁所需的能量, 用电负性大的 $\mathrm{N}$ 或 $\mathrm{S}$ 原子代替 $\mathrm{C}$ 原子, 降低最低空 轨道(LUMO)能级, 从而降低 $E_{\mathrm{g}}$, 实现红移. ${ }^{5}$ 此外, 取 代基的种类和位置以及给电子或吸电子能力等都 是影响其发光性能的重要因素, 因此改变配体的取 代基位置或种类, 如引入供电子的烷基、烷氧基等, 也可以调节发光颜色, 使光谱红移. 前人在此领域 已经进行了相当一部分的有意义的探索性工作, 合
成出了多种基于稠杂环化合物的红光磷光材料, 这 类磷光材料集各种功能单元于一体, 它们具有如下 的优点. (1) 发光量子效率高: 稠杂环类铱配合物, 由 于存在强烈的自旋-轨道耦合, 使得其配合物的单重 态激子和三重态激子混杂, 最大内量子效率理论可 达 $100 \%$. (2) 发光颜色可调: 这类配合物对比其它发 光分子而言有着易于制备、便于通过修饰配体来调 节发光波长, 通过改变稠杂环配体和辅助配体, 可 获得发光效率高的纯红光磷光铱配合物. (3) 平衡电 荷注入及迁移能力: 通过引入传电子基团及传空穴 基团到配体中, 调节它们之间的比例可平衡材料的 电荷注入及传输能力, 从而提高器件的稳定性和效 率. ${ }^{6}$ 人们成功地把这些以稠杂环化合物为配体的磷 光材料应用于器件中, 为红色磷光材料的发展做出 了巨大贡献. 铱配合物磷光材料按分子比重可以分 为小分子有机金属配合物, 树枝状金属配合物和高 分子金属配合物. 本文从小分子、树枝状和高分子 铱配合物三个方面着手, 阐述了稠杂环化合物在红 光磷光铱配合物中的应用, 展望了稠杂环化合物在 红光磷光材料中的应用前景.

\section{2 基于稠杂环化合物的小分子红色磷光铱 配合物}

\section{1 以喹啉、异喹啉类化合物为配体的红色磷光铱 配合物}

铱配合物的发光性质与主配体以及辅助配体 的结构有很大关系. 配体的共轭程度、刚性大小、取 代基的种类和位置以及给电子或吸电子能力等都 是影响其发光性能的重要因素. 喹啉和异喹啉类衍 生物由于其不错的电子亲和能力被广泛使用在发 光化学中. 8-差基喹啉铝及其衍生物以成为比较经 典的电子传输材料. 近些年来, 以喹啉和异喹啉衍 生物为配体的铱配合物(图 1)已被证明拥有良好的 磷光性能.

Tsuboyama ${ }^{7}$ 和 Baranoff ${ }^{8}$ 等报道了多种磷光材 料, 他们通过增大配体分子的共轭长度或者引入给 电子基团, 降低三线态激子能量, 使发光波长红移, 其中 $\mathrm{A1} 、 \mathrm{A2}$ 和 $\mathrm{A3}$ 三种材料发射红光, 它们在室温 下的发光峰值波长分别为 $620 、 644$ 和 $652 \mathrm{~nm}$. 当将 


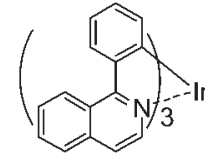

A1

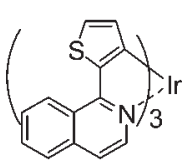

A2

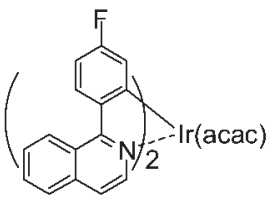

A6

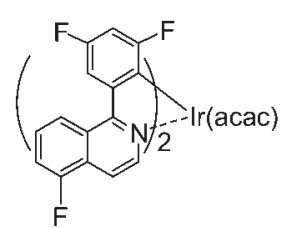

A7

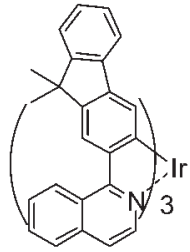

A3

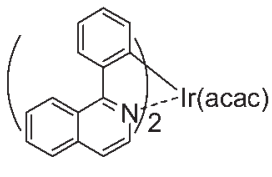

A4

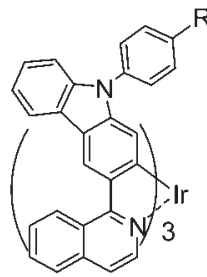

A8

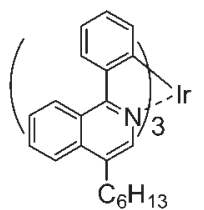

A9

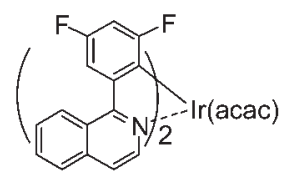

A5

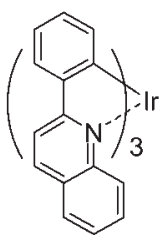

A10

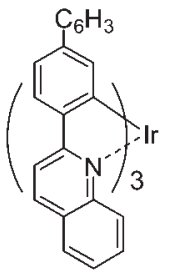

A11

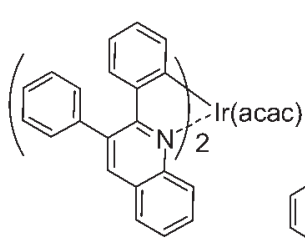

A12

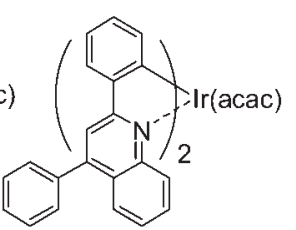

A13

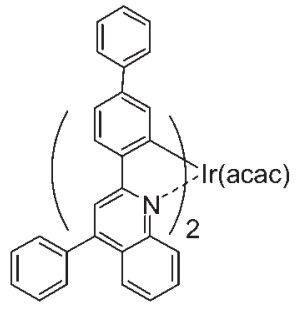

A14

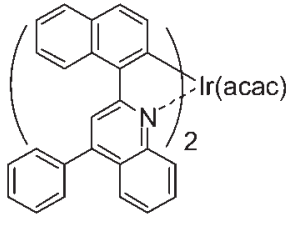

A15

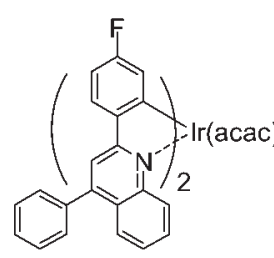

A16

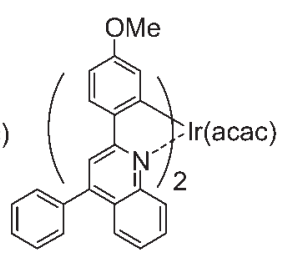

A17

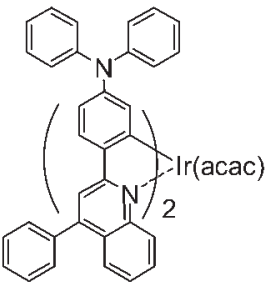

A18

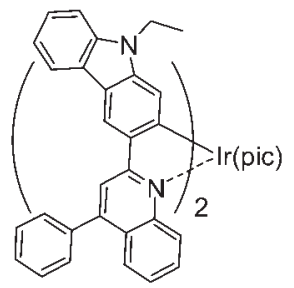

A19

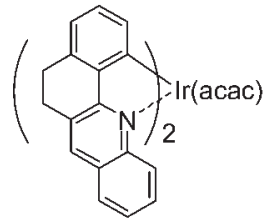

A20

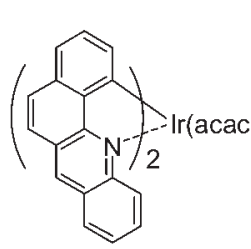

A21

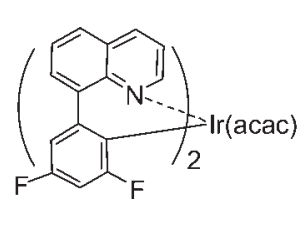

A22

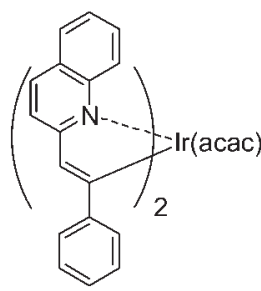

A23

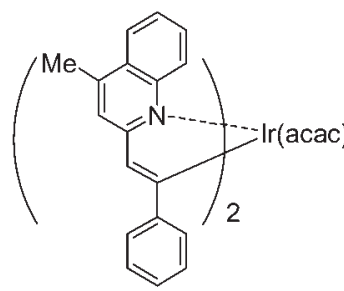

A24<smiles>CC(C)(C)C(=Cc1cccc2ccccc12)c1ccccc1</smiles>

A25

图 1 基于喹啉和异喹啉衍生物的红色磷光铱(III)配合物

Fig.1 Red phosphorescent iridium(III) complexes based on quinoline and isoquinoline derivatives acac: acetylacetonate, pic: 2-picpolinic acid

9\% (w) 的 A1 掺杂到主体材料 4,4'-二(9-咔唑)联苯 (CBP) 中, 在亮度为 $100 \mathrm{~cd} \cdot \mathrm{m}^{-2}$ 时外量子效率达到 $10.3 \%$, 在 $300 \mathrm{~cd} \cdot \mathrm{m}^{-2}$ 时外量子效率为 $9.6 \%$, 其色坐 标(CIE)为 $(0.68,0.32)$, 是色纯度较好的红光材料.

$\mathrm{Li}^{\text {等 }}{ }^{9}$ 也合成了一系列具有较短磷光寿命的红 色磷光铱配合物 A4-A7, 它们具有较长的发光波 长, 发射饱和红光. 由于分子间重叠造成的相互作
用使激子具有非常短的激子寿命 $(<0.5 \mu \mathrm{s})$, 有效减 少了三线态-三线态 $(\mathrm{T}-\mathrm{T})$ 激子淬灭, 特别是高电流 下仍能获得高的发光效率. 分别将 $6 \%(w)$ 的配合物 A4、A7 掺杂在 CBP 中, 在电流密度为 $20 \mathrm{~mA} \cdot \mathrm{cm}^{-2}$ 时 外量子效率分别为 $8.46 \%$ 和 $10.15 \%$, 色坐标分别为 $(0.68,0.32)$ 和 $(0.68,0.31)$. 在 $400 \mathrm{~mA} \cdot \mathrm{cm}^{-2}$ 时, 效率 仍高达 7\%和 6.5\%. 因此可见, 缩短配合物中激子寿 
命是解决磷光器件发光效率随电流增大急剧下降 的一个有效途径.

$\mathrm{Ho}$ 等 ${ }^{10}$ 报道了适用于旋涂及蒸镀法的基于咔 唑-异喹啉衍生物的铱配合物 A8. 采用旋涂法制备 的器件发射红光, 色坐标为 $(0.67,0.33)$, 外量子效率 达到 $12 \%$. 具有空穴传输特性的咔唑基团的引入能 够提高电致发光过程中的电荷平衡性.

Meng 等 ${ }^{11}$ 对比了四种红光磷光材料 A1、A9、 $\mathrm{A10}$ 和 A11, 发现以含长烷基链的配合物为客体的 器件有更高的效率, 因为长烷基链的引入提高了配 合物的溶解性, 使其能够更加均匀地分布在主体材 料中.

Yang 等 ${ }^{12}$ 制得器件亮度高达 $22040 \mathrm{~cd} \cdot \mathrm{m}^{-2}$ 的红 光材料 $\mathbf{A 1 2}$, 掺杂 5\%时, 色坐标为 $(0.66,0.34)$, 电流 效率在 $15 \mathrm{~V}$ 时达到 $11.4 \mathrm{~cd} \cdot \mathrm{A}^{-1}$. Wang 等 ${ }^{13}$ 制备了一 系列以 2-芳基喹啉衍生物为主配体, 乙酰丙酮(acac) 为辅助配体的配合物 $\mathbf{A 1 3}-\mathbf{A 1 8}$, 受主配体吸电子性 及共轭度的影响, 基于这些配合物的器件发光颜色 由橙红到深红. 其中, A16 发橙红光, A13、A14、A18 的发光颜色接近标准红光, 而 A15 则发深红光. 基 于器件 $\mathbf{A 1 3}$ 的器件在 $100 \mathrm{~cd} \cdot \mathrm{m}^{-2}$ 的外量子效率达到 10.4\%. Lee 等 ${ }^{14}$ 将咔唑基团引入主配体, 制得配合物 A19, 将其用旋涂法掺杂在非共轭聚合物聚乙烯基 咔唑(PVK)中制得的红光 OLED 器件, 外量子效率 达到 $10.6 \%$, 明显高于使用传统方法制得的红光 OLED 器件.

目前为止, 铱配合物使用的环金属配体大多数 是基于邻芳基吡啶或邻杂环芳基吡定的衍生物, 从 而使器件的效率、亮度、发光颜色等都依赖环金属 配体, 因此, 可以通过环金属配体的改变提高器件 性能和色纯度, Pan 等 ${ }^{15}$ 设计了两个具有刚性结构的 环金属配体, 基于这两个配体的铱配合物 $\mathbf{A 2 0}$ 和 A21 在二氯甲烷中的发光峰位于 591 和 $665 \mathrm{~nm}$, 将 其作为客体掺杂在发光层制得的纯红光器件, 亮度 达到 $9540 \mathrm{~cd} \cdot \mathrm{m}^{-2}$.

需要指出的是在所有文献报道中出现的铱配 合物都是五元环的, 而 2005 年 $\mathrm{Li}$ 等 ${ }^{16}$ 首次合成了含 有 8-苯基喹啉骨架的六元环铱配合物. 这些配合物 发射深红色磷光, 峰值波长为 650-680 nm. 二(8-(3,5二氟苯基)喹啉(乙酰丙酩))铱(A22)的外量子效率最 大为 $2.04 \%$, 当电压为 $16 \mathrm{~V}$ 时, 半峰宽只有 $60 \mathrm{~nm}$.

Rayabarapu 等 ${ }^{17}$ 还报道了 $\mathbf{A 2 3} 、 \mathbf{A 2 4} 、 \mathbf{A 2 5}$ 三种 配合物, 通过选择配体 2-((E)-2-苯基-1-乙烯基)喹啉
(PEQ)、4-甲基-2((E)-2-苯基-1-乙烯基)喹啉(MPEQ) 和 1-((E)-2-苯基-1-乙烯基)异喹啉(PEIQ), 增大了配 体的共轭度, 使发光红移, 获得了饱和的红光发射.

\section{2 以喹喔啉类化合物为配体的红色磷光铱 配合物}

作为磷光材料最好要具有一定的环状共轭结 构的有机配体, 这样容易引入相关分子结构发光. 一般来说, 有机配体的共轭程度越大, 配合物共轭 平面和刚性结构程度越大, 配合物的发光效率就越 高. ${ }^{18}$ 因为这种结构稳定性大, 可以大大降低发光的 能量损失. 目前对于含氮杂环配体的研究主要侧重 于三环及多环体系. ${ }^{19}$ 含有两个氮原子的六元稠杂 环的喹喔啉与喹啉相比多了一个亚胺氮原子, 使得 其电子亲和势更高, 具有更好的电子注入和传输功 能. 同时, 由于喹喔啉衍生物有较好的热稳定性和 化学稳定性, 容易合成与纯化, 已作为电子传输材 料被广泛用于 OLED. ${ }^{20}$

潘粀等 ${ }^{21}$ 用微波辐射法制得了最简单的喹喔啉 铱配合物 B1, 并研究了它的光谱性质, 结果表明, 配 合物 B1 在 $625 \mathrm{~nm}$ 处有较强的金属配合物三线态的 磷光发射, 是一种新型红色磷光材料(图 2). 张国林 等 ${ }^{22}$ 采用微波辐射加热方法, 快速合成了一种新型 三环金属铱配合物 B2, 其吸收光谱显示为 ${ }^{1} \mathrm{MLCT}$ (单线态金属-配体电荷转移) 和 ${ }^{3} \mathrm{MLCT}$ (三线态金 属-配体电荷转移)吸收. 在室温下, 该配合物在 634 $\mathrm{nm}$ 处具有较强的光致磷光发射, 有望成为一种新型 红色磷光材料. 将以此喹喔啉类化合物为配体的双 环金属配合物 B3 掺杂在主体 $N, N^{\prime}$-二-(1-荎基)- $N$, $N^{\prime}$-二 - 苯基-(1,1'-联苯)-4,4'-二胺(NPB)中作为发光 层, 以 2-(4'-叔丁基苯)-5-(4"'-联苯基)-1,3,4-噁二唑 (PBD) 为电子传输材料制备了结构为 $\mathrm{ITO} / \mathrm{NPB}(30$ $\mathrm{nm}) / \mathrm{NPB}: 7 \%$ B3(25 nm)/PBD(10 nm)/Alq $3(30 \mathrm{~nm}) /$ $\mathrm{Mg}: \operatorname{Ag}(10: 1)(120 \mathrm{~nm}) / \operatorname{Ag}(10 \mathrm{~nm})$ 的电致磷光器件, 并研究了器件的电致发光性能. 结果表明, 该器件 的启动电压是 $4.25 \mathrm{~V}$, 器件的最大亮度为 $4910 \mathrm{~cd}$. $\mathrm{m}^{-2}$, 外量子效率为 $5.14 \%$, 器件的流明效率为 1.12 $\mathrm{lm} \cdot \mathrm{W}^{-1}$, 是一种新型红色磷光材料. 23

Johannes 等 ${ }^{24}$ 在 2 -苯基喹喔啉(PQ)上引入甲基 和氟原子, 分别制得以 2-吡啶甲酸(pic)、乙酰丙酮和 吡啶三氮唑(trz) 为辅助配体的配合物 B4、B5 和 B6, 受氟原子强吸电子性的影响 B5 的发射光谱比 B3 蓝 移了 $32 \mathrm{~nm}$. 受辅助配体的影响, B5 的发射峰比 B4 和 B6 红移了大约 $20 \mathrm{~nm}$. 基于配合物 B4 的电致发 


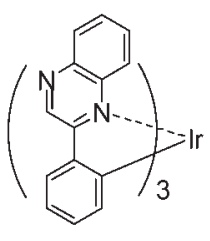

B1

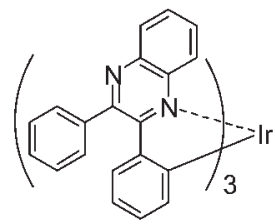

B2

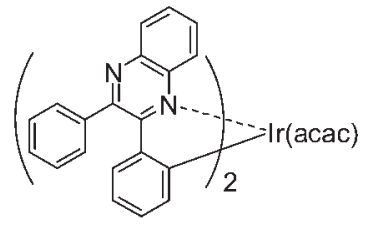

B3

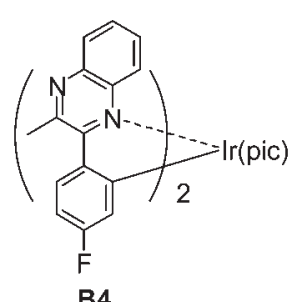

B4

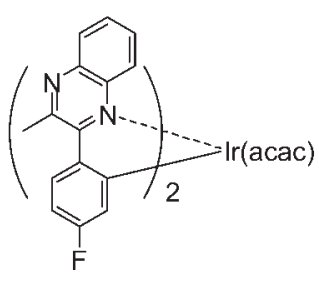

B5

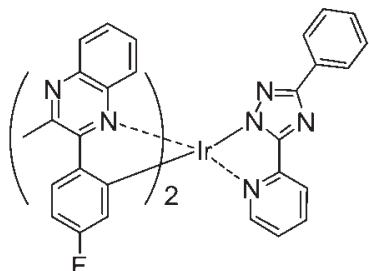

B6

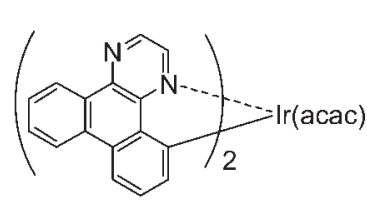

B9

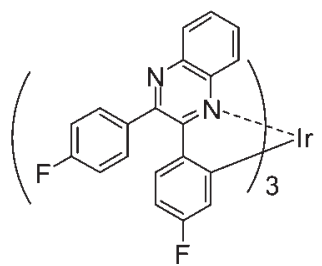

B7

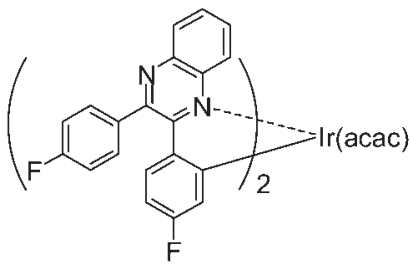

B8

图 2 基于芳基喹喔啉衍生物的红色磷光铱(III)配合物

Fig.2 Red phosphorescent iridium(III) complexes based on quinoxaline derivatives

光器件有高达 $14.6 \mathrm{~lm} \cdot \mathrm{W}^{-1}$ 的能量效率, $\mathrm{Ha}$ 等 ${ }^{25}$ 在 B2 上引入两个氟原子, 使发光颜色蓝移了 $28 \mathrm{~nm}$, 结 构为 ITO $/ 2-\mathrm{TNATA} / \mathrm{NPB} / 10 \% \mathbf{B} 7: \mathrm{CBP} / \mathrm{BCP} / \mathrm{Alq}_{3} / \mathrm{Liq} /$ $\operatorname{Al}$ (2-TNATA: $4,4^{\prime}, 4^{\prime \prime}$-tris-( $N$-naphthylen-2-yl)- $N$-phenylamine)triphenylamine; $\mathrm{Alq}_{3}$ : tris(8-hydroxyquinolinato)aluminium; Liq: 8-hydroxyquinolinolato-lithi$\mathrm{um})$ 的器件亮度为 $3570 \mathrm{~cd} \cdot \mathrm{m}^{-2}$, 亮度效率为 4.18 $\mathrm{cd} \cdot \mathrm{A}^{-1}$. 张国林等 ${ }^{26}$ 也把氟原子引入配合物 $\mathbf{B} 3$, 从而 使发光颜色蓝移了 $18 \mathrm{~nm}$.

Cheng 等 ${ }^{27}$ 报道了两种带有二苯并喹喔啉 (DBQ)和 2-甲基苯并喹喔啉(MDQ)配体的材料 $\mathbf{B 9}$ 和 B10 发射橙红色光, 最大外量子效率为 $12.4 \%$.

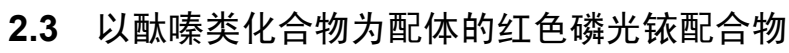

Hay 等 ${ }^{28,29}$ 合成了结构新颖的杂环化合物 4-(4羟苯基)-1-酞嗪酮. 该化合物在一个芳环中含有两 个相邻的氮原子, 具有扭曲的杂环联苯结构, 并可 以与双卤单体发生聚合, 制备一系列聚芳醚酮和聚 芳醚砜, 所得改性聚芳醚酮的玻璃化温度 $\left(T_{\mathrm{g}}\right)$ 在 241-309 ${ }^{\circ} \mathrm{C}$ 间, 热稳定性非常高, 并且这些聚合物 均可溶于氯仿等常规有机溶剂, 并可带有活性基 团, 应用范围广. 这种基于 $\mathrm{C}^{\wedge} \mathrm{N}=\mathrm{N}$ 型配体的铱配合 物, 与常见的含 $\mathrm{C}^{\wedge} \mathrm{N}=\mathrm{CH}$ 配体的铱配合物相比, 配
位 $\mathrm{N}$ 原子与 $\mathrm{Ir}$ 原子的键距更短, 键能更大. 具有这种 结构的材料更容易合成并有很高的热稳定性, 基于 该材料的电致发光器件也有很长的使用寿命. 芳基 酞嗪衍生物还具有如下特点: ${ }^{6}(1)$ 杂环的碱性比吡 啶弱, 这样杂环不易被质子化, 即使质子化后也容 易脱去, 并参与配位; (2) 杂环的吸电子能力比吡啶 强, 使得联苯上的氢原子容易脱去; (3) 与最常见的 $\mathrm{C}^{\wedge} \mathrm{N}=\mathrm{CH}$ 配体比较, 由于未参与配位的 $\mathrm{N}$ 原子上不 含氢原子, 配位反应过程中配体对铱离子的位阻效 应会更小, 易于反应的进行. 这些特点使它比 $\mathrm{C}^{\wedge} \mathrm{N}=\mathrm{CH}$ 类型的环金属配体更易在较为温和的合 成条件下生成三环金属铱配合物. 此外, 当酞嗪衍 生物被位阻较大的取代基取代时, 也能够以较高产 率获得性能优良的双环金属配合物. ${ }^{30}$ 因此, 如果能 以这种杂环作为配体, 有可能开发具有优越性能的 电致磷光配合物(图 3).

Tong 等 ${ }^{31,32}$ 最先把这种类型的配体应用于铱配 合物，报道了内量子效率几乎为 $100 \%$ 的配合物 $\mathbf{C 2}$. 随后, $\mathrm{Mi}$ 等 ${ }^{33}$ 也研究了基于 $\mathrm{C}^{\wedge} \mathrm{N}=\mathrm{N}$ 型配体的铱配 合物 $\mathbf{C 1}$, 掺杂 $5 \%$ 的器件的外量子效率为 $8.3 \%$, 色 坐标为 $(0.69,0.30)$, 虽然该器件效率较低, 却有着较 好的色纯度. C1 被证明是一个很有价值的饱和红光 


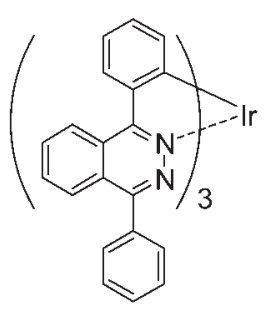

C1

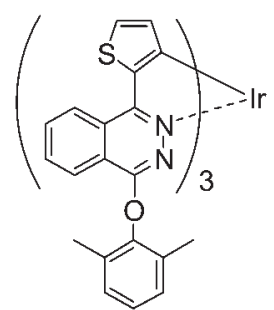

C6

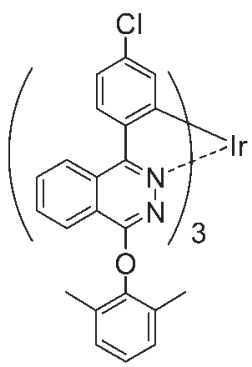

C2

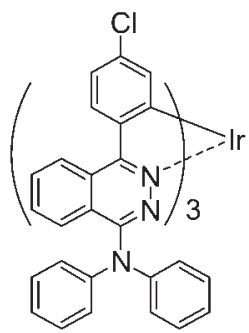

C3

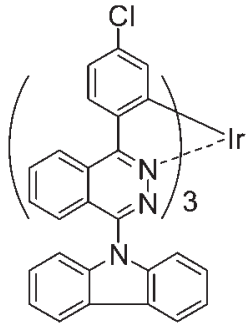

C4

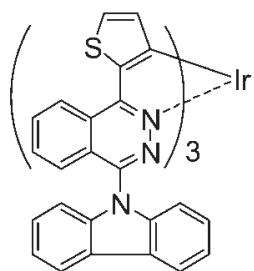

C5

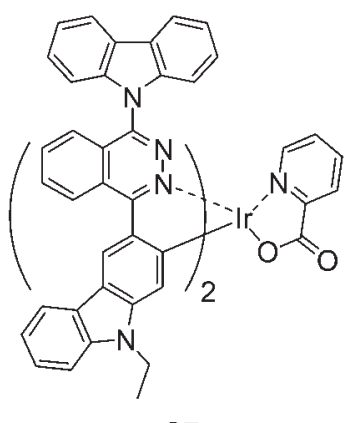

C7

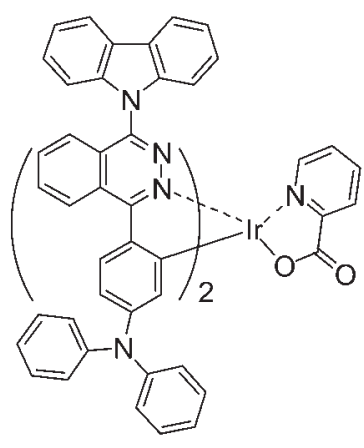

C8

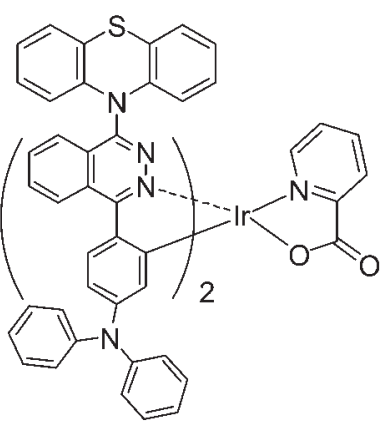

c9

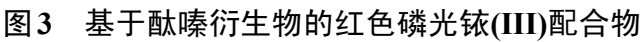

Fig.3 Red phosphorescent iridium(III) complexes based on phthalazine derivatives

材料.

Fang 等 ${ }^{34-36}$ 在酞嗪上引入功能单元二苯胺、咔 唑、噻吩等, 获得一系列性能优异的红光铱配合物 C3-C6. 探讨了不同取代基引入环金属配体, 给相 应的配合物发光性能带来的影响. 例如, 引入二甲 基苯氧基后, 配合物的溶解性极大地增强; 引入空 穴传输基团咔唑后, 在电致发光过程中配合物的载 流子传输特性得到了更好的调节, 可以有效抑制由 于分子聚集产生的三线态-三线态淬灭和浓度淬灭 并且最高占有分子轨道(HOMO) 能级得到提高, 热 稳定性增强. 三苯胺基团的引入同样可以提高材料 的空穴传输性, 并且增加材料的共轭程度. 富电子 的噻吩基团的引入, 增加了配体的共轭程度, 光致 发光和电致发光光谱都出现明显红移. 将这些配合 物掺杂在 OLED 发光层中, 获得了较好的性能. 掺杂 浓度为 2\%时, C4 的外量子效率也达到 20.2\%. 掺杂 $4 \%$ 时, C3、C5 和 C6 的外量子效率分别是 13.6\%、 $10.2 \%$ 和 $7.1 \%$.

我们课题组 ${ }^{30}$ 将咔唑、三苯胺等功能单元引入 环金属配体, 制备了基于酞嗪衍生物的双环铱配合 物 C7、C8 和 C9, 这些功能单元的引入, 提高了配合 物的溶解性、空穴传输能力、热稳定性和成膜性, 另 外这些单元的引入可以产生一定的空间效应, 从而
减少配合物发光中心之间的直接作用, 减少三重态 激子的自淬灭现象, 提高材料的发光性能. 这几个 配合物在二氯甲烷中都有较强的荧光发射, 其发射 峰分别为 $640 、 653$ 和 $649 \mathrm{~nm}$, 是一类新型的红色磷 光材料.

\section{4 以喹唑啉衍生物为配体的红色磷光铱配合物}

喹唑啉类化合物是一类具有良好生物活性的 含氮杂环化合物, 其各种取代的化合物具有良好的 医药和农药生物活性, 作为一种生物碱在农药和医 药等领域有着广泛的应用, 受到化学界和生物学界 的广泛关注, 是研究的热点之一. ${ }^{37-39}$ 目前, 对于喹唑 啉类化合物的研究主要从分子设计、合成及性能研 究着手. 另外, 由于喹唑啉具有强的吸电子性和电 子传输能力, 可起到颜色调节的作用而广泛应用. 过去十年中, 由于良好的器件性能, 以喹唑啉衍生 物为配体的铱配合物(图 4)吸引了人们的广泛关注.

通常, 三重态激子具有较长的激发态寿命, 高 电流下易于饱和, 且增加三重态激子自淬灭效应, 使发光效率降低. 因此, 如果能缩短三重态激子的 寿命则可以大大提高磷光材料的发光效率. Song 等 ${ }^{40}$ 合成了配合物 D1、D2、D3, 其中 D1 和 D3 的最大 发射峰分别为 626 和 $652 \mathrm{~nm}$, 二者都具有非常短的 磷光寿命, 分别为 1.05 和 $0.92 \mu \mathrm{s}$, 可以减少激子㵏 


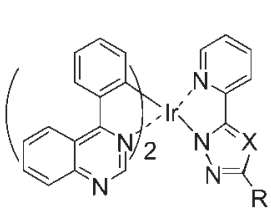

$\mathrm{R}=\mathrm{CF}_{3}, \mathrm{X}=\mathrm{CH}$ D1 $\mathrm{R}=\mathrm{CF}_{3}, \mathrm{X}=\mathrm{N} \quad \mathrm{D} 2$

$\mathrm{R}=\mathrm{Bu}^{\mathrm{t}}, \mathrm{X}=\mathrm{CH} \quad \mathrm{D} 3$

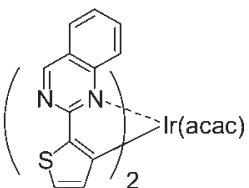

D8

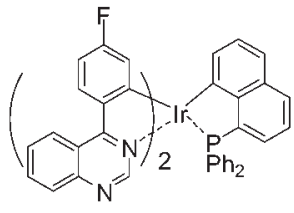

D4

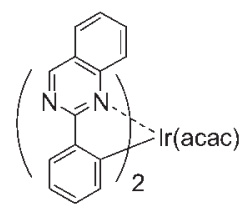

D5

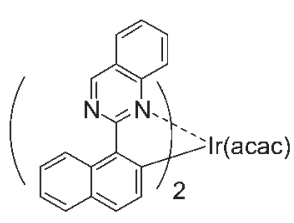

D6

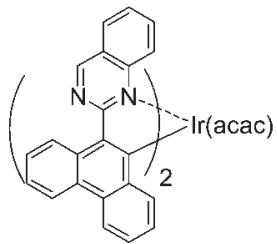

D7

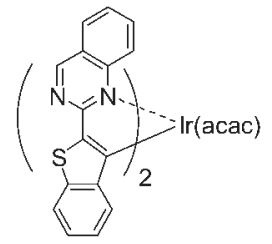

D9

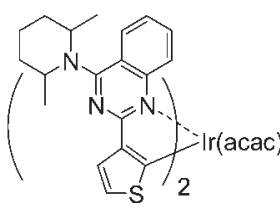

D10

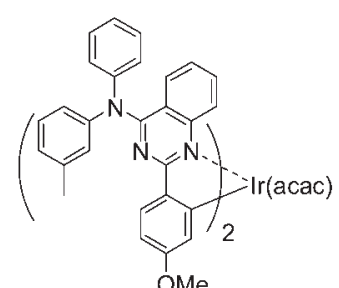

D11

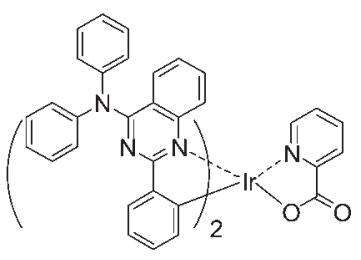

D12

图 4 基于喹唑啉衍生物的红色磷光铱(III)配合物

Fig.4 Red phosphorescent iridium(III) complexes based on quinazoline derivatives

灭, 提高发光效率, 即使对应非掺杂的发光器件也 能获得较高的发光效率. D1 作为发光层的器件, 在 驱动电压为 $8 \mathrm{~V}$ 时, 外量子效率仍能达到 5.5\%, 色坐 标为 $(0.69,0.31)$. Du 等 ${ }^{41}$ 研究了顺、反式结构对配合 物发光颜色及能级的影响, 以含一个氟原子的4-苯 基喹唑啉衍生物为配体制得的顺反两种配合物 D4, 结果表明顺式配合物的发射峰波长小于反式配合 物, 将顺式配合物掺杂主体材料 NSN (4,5-diaza-2,7bis(1-naphthylphenylamino)-9,9-spirobifluorene) 为发 光层的器件的亮度只有 $500 \mathrm{~cd} \cdot \mathrm{m}^{-2}$, 外量子效率达 到了 $10.6 \%$.

Zhang 等 ${ }^{42}$ 公开了一系列含芳基联喹唑啉类金 属铱配合物红色有机电致磷光材料 D5-D9, 结合以 其为掺杂剂的有机电致发光(EL)器件结构的优化, 实现相对于传统红光材料具有更好色纯度和更高 效率的红色电致磷光发射. 其中, 掺杂浓度为 $10.5 \%$ 的配合物 D6 为掺杂剂经热蒸镀法制得的高性能电 致发光器件的最大亮度达到 $14571 \mathrm{~cd} \cdot \mathrm{m}^{-2}$, EL 峰值 是 $629 \mathrm{~nm}$, 色坐标为 $(0.638,0.361)$; 同样以 $\mathrm{Zn}(\mathrm{BTZ})_{2}$ (BTZ: bis[2-(2-benzothiazoly)phenolato]zinc(II)) 为发 光层基质, 10\%的 D5 为掺杂剂制得的电致发光器件 的最大亮度达到 $24338 \mathrm{~cd} \cdot \mathrm{m}^{-2}$, 色坐标为 $(0.596$, 0.403 ), 为制备高亮度红色电致发光器件提供了方 法.

$\mathrm{Hsu}$ 和 $\mathrm{Li}^{43}$ 用固相法合成配合物 D10、D11. 将其 掺杂在主体材料 CBP 中制得红光电致发光器件, 其 中基于 D11 的器件外量子效率高达 $20.3 \%$, 最大亮
度效率为 $16.6 \mathrm{~cd} \cdot \mathrm{A}^{-1}$, 启动电压只有 $4.3 \mathrm{~V}$, 相应的 色坐标是 $(0.666,0.332)$. 这个 CIE 红光结果与美国 电视系统委员会制式的规定完全一致, 这对红光材 料的分子设计有很大的指导意义. 我们课题组 ${ }^{44}$ 也 制备了结构类似的铱配合物 D12, 并将其应用在电 致发光领域. 与 Hsu制备的配合物相比, 我们的配合 物不仅合成方法简单, 反应条件温和, 而且将其掺 杂在混合主体材料 PVK/PBD 中制得的电致发光器 件有着更高的亮度效率, 掺杂浓度为 $8 \%$ 时外量子 效率为 $18.44 \%$, 亮度效率达到 $20.73 \mathrm{~cd} \cdot \mathrm{A}^{-1}$.

\section{5 以苯并含氮五元杂环衍生物为配体的红色磷 光铱配合物}

苯并噻唑及其衍生物是非常重要的一类五元 稠杂环化合物, 具有显著的生物活性和药物活性..$^{4}$ 其结构单元常见于某些抗肿瘤药物, 抗菌药物, 以 及抗帕金森综合症药物中. 近来, 苯并噻唑也被用 于某些有机光电材料, 例如用于二阶非线性光学材 料, ${ }^{46}$ 液晶材料, ${ }^{47}$ 用于构建苂光发色团, ${ }^{48}$ 以及与金 属铱 ${ }^{49}$ 或铂 ${ }^{50}$ 形成环金属配合物用于有机光电二极 管中. 2001 年, Thompson 等 ${ }^{51}$ 报道了一组基于苯并 噻唑的铱的磷光配合物 E1 和 E2 (图 5), 这两个配合 物在 2-甲基四氢呋喃中发红光, 发射峰分别是 606 和 $594 \mathrm{~nm}$.

咪唑类化合物, 尤其是多取代咪唑类化合物, 具有良好的生物活性及药用活性, 在药物中具有非 常重要的地位. ${ }^{52}$ 此外, 咪唑分子本身具有良好的电 子转移性能和易功能化的特点, 常用于有机电致发 


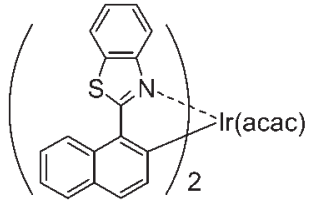

E1

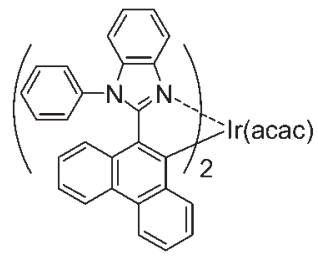

E4

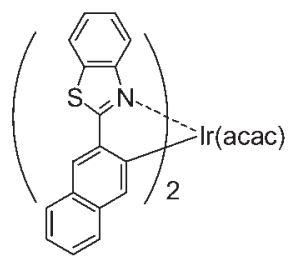

E2

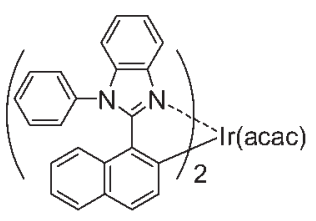

E3

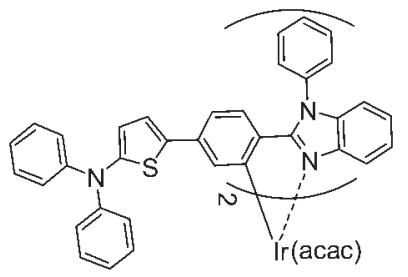

E5

图 5 基于含氮五元杂环化合物的红色磷光铱(III)配合物

Fig.5 Red phosphorescent iridium(III) complexes based on nitrogen containing five-member heterocyclic compounds

光材料的研究. ${ }^{53,54} 2004$ 年, Huang 等 ${ }^{53}$ 报道了一组基 于苯并咪唑结构的铱配合物 E3、E4 和 E5(图 5), 这 些配合物在室温下都有较强的红色磷光. 当以结合 芴环设计的化合物 BPAPF (9,9-bis(4-(di(p-biphenyl) aminophenyl))fluorene)为空穴传输层时, 掺杂 $6 \% \mathrm{E3}$ 的器件最大外量子效率为 $2.6 \%$, 最大亮度为 12874 $\mathrm{cd} \cdot \mathrm{m}^{-2}$, 色坐标为 $(0.63,0.35)$; 当以 $\mathrm{NPB}$ 为空穴传输 层时, 掺杂 $6 \% \mathrm{E3}$ 的器件最大外量子效率为 $1.7 \%$, 最大亮度为 $11598 \mathrm{~cd} \cdot \mathrm{m}^{-2}$.

\section{3 基于稠杂环化合物的树枝状大分子红色 磷光铱配合物}

树枝状磷光化合物 (结构如图 6 所示) 是近几年 发展起来用于发光的新型化合物. 由于树枝状分子 结合小分子和高分子的优点, 不但可以避免磷光中 心聚集, 还可以减小三重态激子淬灭, 又能够采用 溶液处理的方法来制备有机电致发光器件, 一直被 人们认为是成功实现 OLED工业化特别是大面积显 示工业化的重要途径. 树枝状聚合物是由核(core)、 树枝(dendron)、表面基团(surface group)构成的具有 精确的结构和三维形状的可用溶液处理的分子. 由 于带有刚性骨架, 功能基团可以限制在核的部位, 同时树枝和表面基团则可以控制功能基团之间的 相互作用. 表面基团更是决定了分子的处理性能. 因此可以通过调节树枝状聚合物的这三个部分来 实现性能调控和分子构建. 树枝状化合物不仅大大 减轻了三线态激子自淬灭, 而且增强了成膜性, 使 其可以通过溶液旋涂制作器件, 克服了小分子只能
真空蒸镀的不足, 拓宽了有机电致发光器件的应用 范围.

Namdas 等 ${ }^{55}$ 在树枝状铱配合物领域做了大量 工作, 取得了很好的结果, 他们报道了一类结构对 称和非对称的红光树枝形铱配合物 (F1、F2), 研究了 这两种树枝状铱配合物的光物理性质及以此类配 合物为发光层的双层器件的电致发光性能. 基于化 合物 $\mathbf{F} 1$ 的器件的最大外量子效率为 $5.7 \%$, 最大亮 度为 $2740 \mathrm{~cd} \cdot \mathrm{m}^{-2}$. 基于化合物 $\mathbf{F} 2$ 器件的最大外量 子效率为 $4.25 \%$, 最大亮度为 $1040 \mathrm{~cd} \cdot \mathrm{m}^{-2}$. 同年, 该 小组 ${ }^{56}$ 还报道了几种类似的树枝状配合物 $(\mathbf{F 3})$, 并 比较了对称和非对称结构的铱配合物的光物理性 质. 对于非对称结构的配合物来说, MLCT 态与能 形成最低 HOMO-LUMO 能级差的配体有关, 而不 是所有配体的平均. 比较对称和非对称树枝状配合 物的量子产率, 当树枝连在 MLCT 所在的配体上 时, 能够减少核-核相互作用因此减少了固态下的 苂光淬灭.

Getautis 等 ${ }^{57}$ 合成了一种含空穴传输单元咔唑 的树枝状多功能磷光铱配合物 F4. 这种配合物不仅 具有无定形结构, 而且具有很好的溶解性. 咔唑与 磷光铱中心的屏蔽作用可增加激发态的寿命. 此配 合物的 PL 发射峰在 $650 \mathrm{~nm}$, 苂光寿命只有 $5.7 \mu \mathrm{s}$, 溶液下的苂光量子效率为 0.22 . 非掺杂器件的最大 外量子效率为 $1.81 \%$, 色坐标为 $(0.61,0.33)$. 李裏宏 等 ${ }^{58}$ 报道了一种外围为荎环的茮醚型树枝状红光铱 配合物 F5, 配合物在乙腈/四氢呋喃中的 PL 发射峰 位于 $614 \mathrm{~nm}$. 


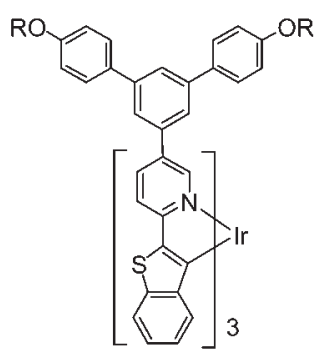

F1

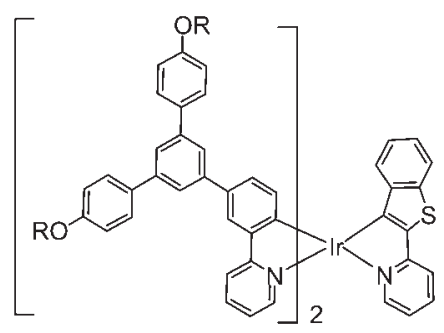

F2

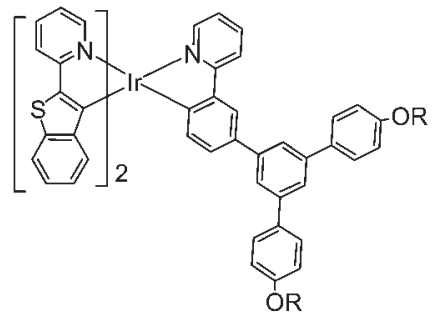

F3

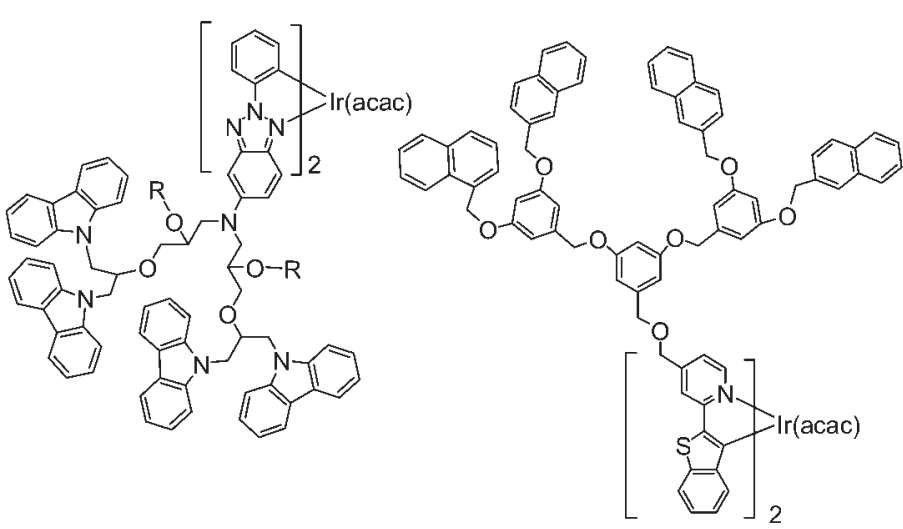

F4

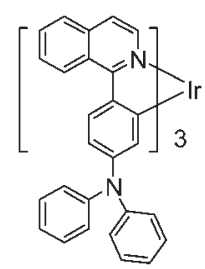

F6

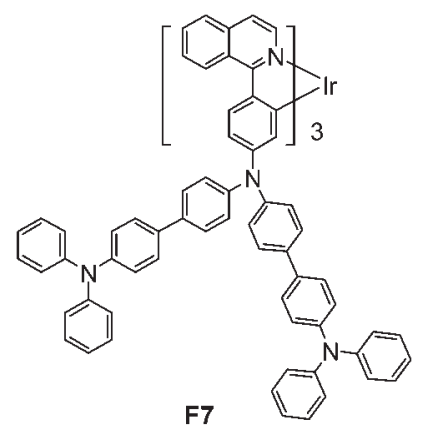

F7

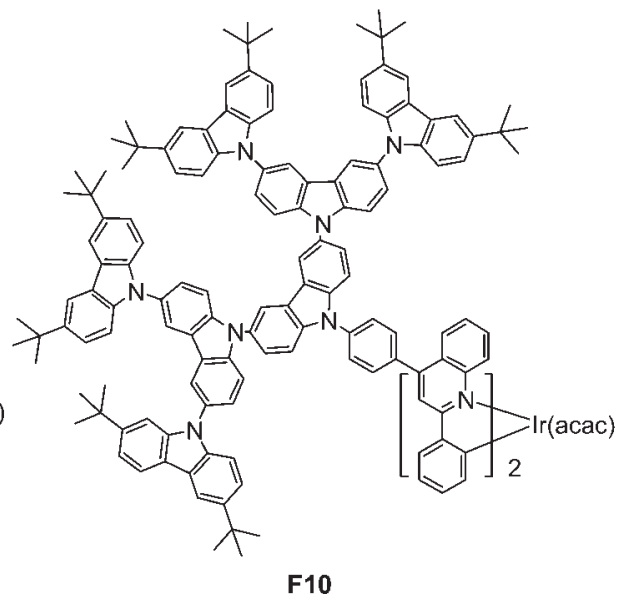

F10

图 6 基于稠杂环化合物的树枝状大分子红色磷光铱(III)配合物

Fig.6 Red phosphorescent iridium(III) coordinating dendrimer complexes based on fused-heterocyclic compounds

另外, 具有不同代数的树枝状铱配合物以及代 数对配合物性能的影响也有报道. 研究发现, 树枝 状铱配合物的代数对其发光性能有影响. 纯的、非 掺杂的树枝状铱配合物薄膜的光致发光量子产率 随着代数的增加而升高, 证明树枝状结构能够控制 分子间的相互作用. Wong 小组 ${ }^{59}$ 将三苯胺引入到树 枝状聚合物的树枝上, 得到不同代数的纯红色发光 的高效树枝状配合物(F6、F7), 研究了不同代数铱配 合物的光致发光和电致发光性质, 发现光致发光和 电致发光的量子效率均随代数的增加而升高. 将第
二代配合物 F7 掺杂到 CBP 中制备的器件, 最大外 量子效率为 $7.36 \%$, 亮度达到 $6205 \mathrm{~cd} \cdot \mathrm{m}^{-2}$. Wang 等 ${ }^{60}$ 也报道了三组不同代数的树枝状红光铱配合物 $\mathbf{F 8}$ 、 F9、F10. 除了能够控制分子间的相互作用, 将寡聚 咔唑接枝到第三代铱配合物还参与电化学和电荷 传输过程. 他们用旋涂法制得了高性能的磷光器 件. 基于第三代配合物 F10 的非掺杂器件的最大外 量子效率达到 6.3\%, 比第一代配合物 F8 高 30 倍. 当 将 F10 掺杂到咔唑化合物主体中后制备的器件, 外 量子效率提高到 $11.8 \%$. 由此可见, 树枝状铱配合物 
也是一种在电致发光领域具有强劲应用潜力的发 光材料.

\section{4 基于稠杂环化合物的高分子红色磷光铱 配合物}

由于小分子铱配合物存在易结晶、相分离等缺 点, 人们开始注重高分子铱配合物的研究. 用化学 方法将金属配合物引入高分子主链或侧链, 可以减 小磷光中心聚集, 磷光体在聚合物基体中的稳定性 增加产生有效的分子内能量传递或者将激子直接 陷在磷光单体上, 有利于磷光体与主体的均匀分散 和避免相分离从而提高发光效率. 这是同时提高电 磷光聚合物量子效率和迁移率的有效途径. 目前合 成的红色磷光聚合物多是将已报道的典型红光铱 配合物接到宽带隙的共轭聚合物(如聚苆、聚咔唑、 聚苯均聚物或共聚物)主链或侧链上, 从而实现从聚 合物链到铱配合物的能量转移, 发射出铱配合物的 高效红光.

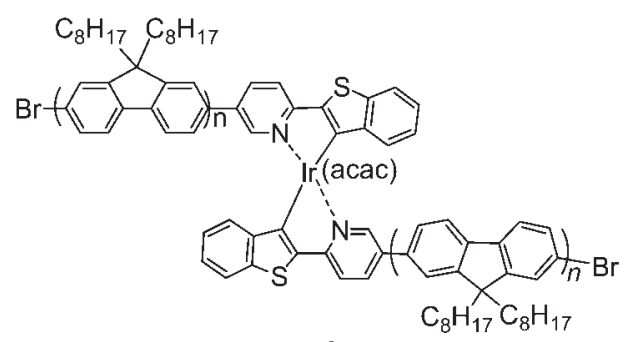

G1

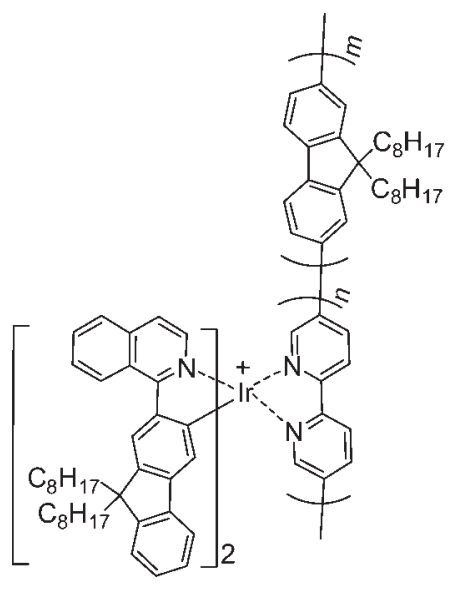

G3

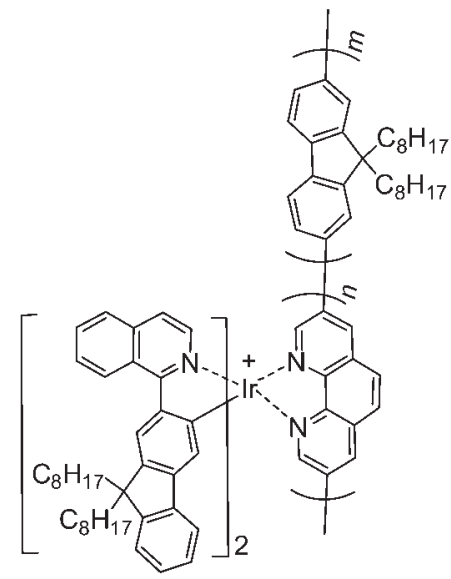

G4

\section{1 主链型高分子铱配合物}

在刚性共轭聚合物主链上引入铱配合物是实 现高效、稳定聚合物电致发光器件(PLED)的有效方 法. 主链含有铱配合物的共轭聚合物(图 7), 由于分 子间的陷阱机制, 能够实现从主链到配合物的高效 能量转移, 减少浓度淬灭和 T-T 淬灭, 器件的效率不 会随电流密度的增加而明显降低. ${ }^{61}$

剑桥大学的 Sandee 等 ${ }^{62}$ 报道了以 (btp $)_{2} \operatorname{Ir}(\mathrm{acac})$ 为发光材料的主链型共轭磷光聚合物 (G1). 他们 通过 Suzuki 反应将芴的齐聚物 (FO) $n$ 与配合物 $(\mathrm{btp})_{2} \operatorname{Ir}(\mathrm{acac})$ 连接, 合成了红光聚合物 $\operatorname{Ir}(\mathrm{btp}-$ $\left.(\mathrm{FO})_{n}\right)_{2}(\mathrm{acac})(\mathbf{G 1})$. 增加芴的重复单元数可以使配 合物的发射光谱发生红移. 该聚合物在未掺杂条件 下易旋涂成膜, 即使在低的铱配合物含量情况下, 聚合物器件的发射仍为三线态发射. 结果表明, 这 种共价键合的共轭主链型铱配合物不仅可以调节 发光波长, 而且比简单的掺杂发光效率高, 为单层 聚合物器件提供了广阔的前景.
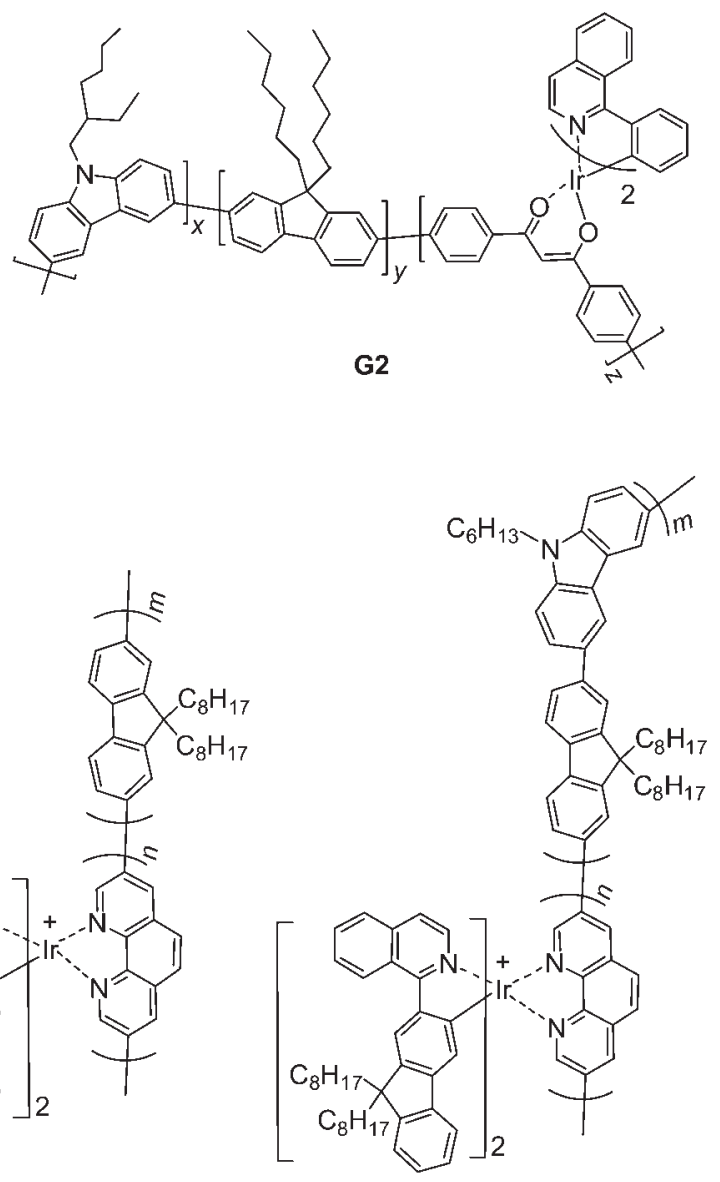

G5

图 7 主链含铱(III)配合物的聚合物红光磷光材料

Fig.7 Main-chain polymer red phosphorescent iridium(III) complexes 
Cao 等 ${ }^{63}$ 也报道了主链上同时含有铱配合物、芴 和咔唑单元的共轭聚合物 $\mathbf{G 2}$, 实现了主、客体之间 的有效能量传递, 即使配合物的含量仅为 $0.5 \%(x)$, 聚合物的发射峰也主要是铱配合物的三线态发射. 他们将这类聚合物作为发光层掺杂到 PBD 中制得 PLED, 得到发光峰为 $628 \mathrm{~nm}$, 最大外量子效率为 $0.6 \%$, 最大亮度为 $541 \mathrm{~cd} \cdot \mathrm{m}^{-2}$ 的饱和红光器件.

Liu等 ${ }^{64,65}$ 报道了一系列主链含铱配合物的 $\pi$-共 轭聚合物 G3、G4、G5, 获得了均匀磷光红光高分子 材料. 在固态时, 配合物含量为 4\% (x), 能量几乎完 全由主体传递给了铱配合物. 而在相应的共混体系 的薄膜中, 甚至铱配合物的含量高达 $16 \%(x)$ 时, 能 量也没有完全转移, 说明分子内的能量传递比分子 间能量传递更有效. 另外, 这些共轭聚合物都具有 良好的热稳定性、氧化还原可逆性和成膜性. 同时, 这些聚合物也表现出比相应的混合体系更有效的 能量传递和通过共轭将铱配合物引入聚合物的机 制, 有效地避免了共混体系的内在问题, 为将 $\pi$-共轭
聚合物应用于光电领域提供了依据. 以不含咔唑的 聚合物 G4 为发光层的聚合物器件在 $20 \mathrm{~V}$ 时电流密 度和亮度分别为 $453.2 \mathrm{~mA} \cdot \mathrm{cm}^{-2}$ 和 $83 \mathrm{~cd} \cdot \mathrm{m}^{-2}$, 以含 咔唑的聚合物 $\mathbf{G 5}$ 为发光层的器件在 $21 \mathrm{~V}$ 时电流密 度和亮度分别为 $265.8 \mathrm{~mA} \cdot \mathrm{cm}^{-2}$ 和 $100 \mathrm{~cd} \cdot \mathrm{m}^{-2}$. 两者 的启动电压都是 $9 \mathrm{~V}$, 而且都是饱和红光. 说明在刚 性共轭聚合物链上引入磷光配合物是实现高效、稳 定性好和易加工的磷光高分子发光二极管的有效 方法.

\section{2 侧链型高分子铱配合物}

由于非共轭聚合物操作电压高, 传导性差, 将 铱配合物引入到共轭聚合物上(图 8) 可以改善这一 问题. 2003 年, Tokito 等 ${ }^{66}$ 报道了含有咔唑和铱配合 物的共轭聚合物 H1, 并通过分子内能量传递实现磷 光发射, 咔唑基团的引入有助于降低空穴注入的势 垒. 将聚合物作为发光层制得了红光器件, 外量子 效率高达 5.5\%. Jiang 等 ${ }^{67}$ 将 1-苯基异喹啉(piq)的铱 配合物接到芴和咔唑的无规则共聚物的侧链上, 合

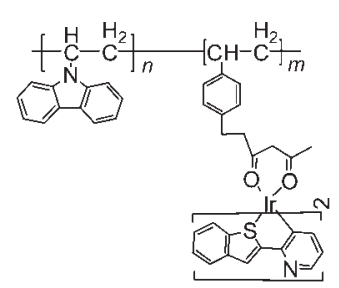

H1

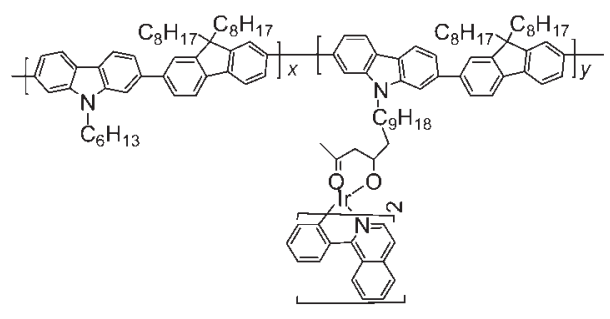

$\mathrm{H} 2$

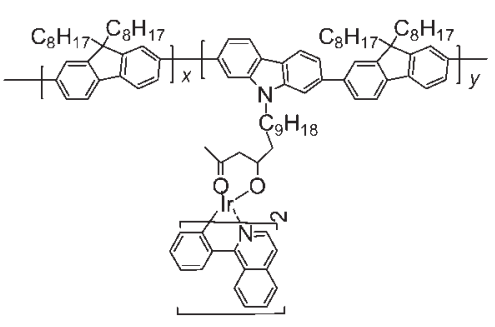

$\mathrm{H3}$

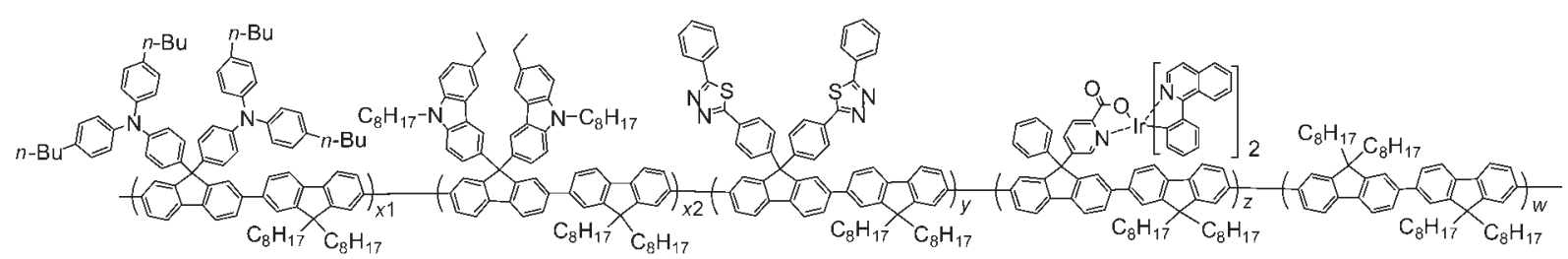

$\mathrm{H} 4$

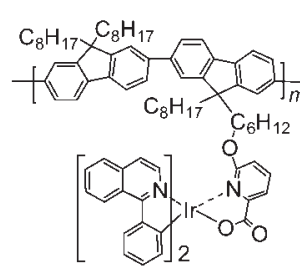

H5

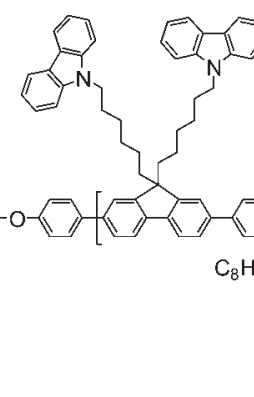

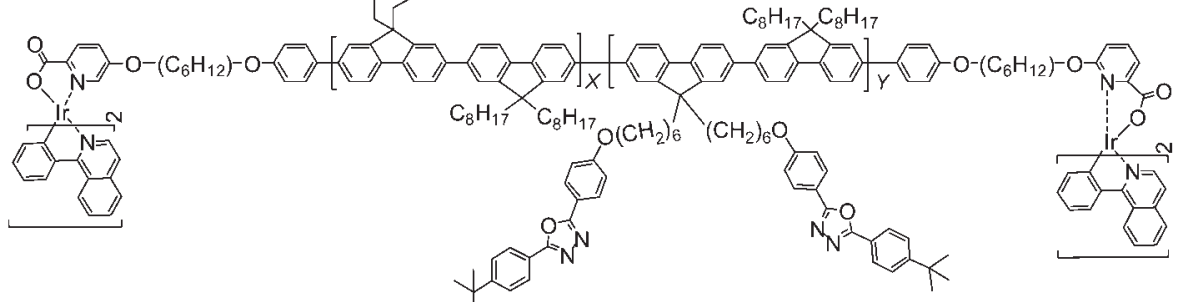

$\mathrm{C}_{8} \mathrm{H}_{17} \times \mathrm{C}_{8} \mathrm{H}_{17}$

H6

图 8 侧链含铱(III)配合物的聚合物红光磷光材料

Fig.8 Side-chain polymer red phosphorescent iridium(III) complexes 
成了侧链含有铱配合物和咔唑的聚合物 $\mathrm{H2} 、 \mathrm{H3}$, 他 们将铱配合物含量为 $0.5 \%(x)$ 的聚合物 $\mathbf{H 2}$ 掺杂在 PBD 中作为发光材料, 制备的器件外量子效率最大 为 $4.9 \%$, 发射峰波长为 $610 \mathrm{~nm}$; 当电流密度为 100 $\mathrm{mA} \cdot \mathrm{cm}^{-2}$, 亮度为 $2978 \mathrm{~cd} \cdot \mathrm{m}^{-2}$ 时, 器件效率仍然很 高, 外量子效率为 $3.4 \%$, 器件性能的提高可以归因 于较高的三线态能级, 此外在聚茀主体的 3,6 位引 入咔唑单元, 或者与 PBD 共混都可以有效提高电荷 注入. Yang 等 ${ }^{68}$ 报道了一系列含有聚芴骨架的磷光 聚合物 H4, 这些聚合物中芴的 9 号位不仅被红光铱 配合物取代, 而且还被三苯胺、咔唑、噁二唑等传输 单元代替. 研究发现空穴传输基团的含量可以影响 聚合物的电致发光性能. 结构为 ITO/PEDOT:PSS/ PFB interlayer/polymer/CsF/Al 的饱和红光器件器件 的最大发光效率和最大功率效率分别为 $9.3 \mathrm{~cd} \cdot \mathrm{A}^{-1}$ 和 $10.5 \mathrm{~lm} \cdot \mathrm{W}^{-1}$.

Zhu 等 ${ }^{69}$ 合成了一系列芴-alt-惡二唑的共聚物 H5, 二氯甲烷溶液中, 这些共聚物具有相似的吸收 光谱和属于芴-alt-噁二唑的典型荧光发射. 但是在 薄膜下, 可以观察到明显属于铱配合物(piq) $2 \operatorname{Ir}(p i c)$ 的红光发射. 将这些聚合物作为单一发光层的聚合 物电致发光器件在 $623 \mathrm{~nm}$ 有饱和的红光峰. 另外, 聚合物中铱配合物的含量对电致发光光谱也有显 著影响, 铱配合物含量是 3\% (x) 时器件的最大亮度 高达 $1125 \mathrm{~cd} \cdot \mathrm{m}^{-2}$. 同年, 该小组 ${ }^{70}$ 又报道了另一组基 于给受体(D-A)聚芴衍生物的共轭聚合物 H6, 这组 聚芴的 9 号位被空穴传输基团咔唑和电子传输基团 噁二唑取代, 用游离的铱配合物封端. 给受体的摩 尔比对这些聚合物的发光效率、电化学和电致发光 性能都有显著影响. 当给受体比例增加至 3:7, 基于 该聚合物的结构为 ITO/PEDOT/polymer/LiF/Al 的 红光聚合物发光器件表现出最佳的性能, 启动电压 是 $6.0 \mathrm{~V}$, 最大电流密度是 $0.59 \mathrm{~cd} \cdot \mathrm{A}^{-1}$, 最大亮度达 到 $917 \mathrm{~cd} \cdot \mathrm{m}^{-2}$.

\section{5 结论与展望}

金属有机配合物电致磷光材料在近几年里倍 受关注, 得到了很大的发展, 各种性质优良的磷光 客体材料相继被开发出来. 器件的效率、亮度和寿 命越来越高, 逐步达到和满足商业化的需求. 但是 红光磷光材料研究还远远落后, 选择合适的红光材 料成为亟待解决的问题. 稠杂环化合物因其优越的 性能被广泛应用于红光铱配合物磷光材料. 研究表
明, 通过改变稠杂环化合物的类型, 对稠杂环化合 物进行功能化等手段可以改善器件稳定性, 提高器 件效率和发光亮度, 获得性能优异的红光磷光器 件. 但是, 目前研究得最多、最深入的仍是喹啉、异 喹啉类铱配合物, 超支化和高分子配合物也主要集 中基于这两类环金属配体的配合物上,而对于一些 新颖的、性能优异的稠杂环类配合物, 如酞嗪类铱 配合物和喹唑啉类铱配合物的报道则较少, 基于此 类配合物的超支化和高分子配合物的研究还是空 白. 如将这些性能优异、色纯度高的小分子铱配合 物应用到树枝状铱配合物的设计合成中, 有利于简 化器件的结构, 减少固态下荧光淬灭, 增加激发态 寿命, 也是电致磷光材料的一个重要研究方向. 此 外，也可将这些性能优异、色纯度高的小分子铱配 合物设计成高分子铱配合物, 这样, 这些材料不仅 具有小分子铱配合物良好的发光特性, 又具备聚合 物优异的物理性能, 如易弯曲、加工成型, 特别是可 溶性聚合物还具有优良的机械性能和良好的成膜 性, 降低制备多层器件面临的多层结构在序列旋涂 过程中混溶的难题, 简化器件制作工艺, 从而减少 浓度淬灭和 T-T 淬灭, 提高器件稳定性. 在今后的研 究中, 焦点仍将集中在铱配合物磷光材料的开发, 那些性能优异的小分子配合物将被进一步拓展到 超支化、高分子领域, 将会有更多性能优异的稠杂 环化合物被开发出来并应用于铱配合物中, 促进铱 配合物电致磷光材料的优化和器件性能的提升.

\section{References}

(1) Baldo, M. A.; Thompson, M. E.; Forrest, S. R. Nature 2000, 403, 750. doi: $10.1038 / 35001541$

(2) Lamansky, S.; Djurovich, P.; Murphy, D.; Abdel-Razzaq, F.; Kwong, R.; Tsyba, I.; Bortz, M.; Mui, B.; Bau, R.; Thompson, M. E. Inorg. Chem. 2001, 40, 1704. doi: 10.1021/ic0008969

(3) Adamovich, V. I.; Cordero, S. R.; Djurovich, P. I.; Tamayo, A.; Thompson, M. E.; D'Andrade, B. W.; Forrest, S. R. Organic Electronics 2003, 44, 77

(4) Hong, H. W.; Chen, T. M. Mater. Chem. Phys. 2007, 101, 170. doi: 10.1016/j.matchemphys.2006.03.011

(5) Wang, X. Synthesis of Red-emitting Iridium Complexes and Their Electrophosphorescence Devices. Ph.D. Dissertation, Dalian University of Technology, Dalian, 2011. [王 馨. 红光 铱配合物的合成及电致磷光器件的性能研究 $[D]$. 大连: 大连 理工大学, 2011.]

(6) Tong, B. H. Synthesis and Properties of Electrophosphorescent and Molecular Hybrid Luminescent Materials. Ph.D. Dissertation, Sun Yat-sen University, Guangzhou, 2008. [ [童碧 
海. 电致磷光与分子杂化发光材料的制备与性能研究 $[D]$. 广 州: 中山大学, 2011.]

(7) Tsuboyama, A.; Iwawaki, H.; Furugori, M.; Mukaide, T.; Kamatani, J.; Igawa, S.; Moriyama, T.; Miura, S.; Takiguchi, T.; Okada, S.; Hoshino, M.; Ueno, K. J. Am. Chem. Soc. 2003, 125 , 12971. doi: $10.1021 / \mathrm{ja} 034732 \mathrm{~d}$

(8) Baranoff, E.; Yum, J. H.; Grätzel, M.; Nazeeruddin, M. K. Journal of Organometallic Chemistry 2009, 694, 2661. doi: 10.1016/j.jorganchem.2009.02.033

(9) Li, C. L.; Su, Y. J.; Tao, Y. T.; Chou, P. T.; Chien, C. H.; Cheng, C. C.; Liu, R. S. Adv. Funct. Mater. 2005, 15, 387. doi: 10.1002/ adfm. 200305100

(10) Ho, C. L.; Wong, W. Y.; Gao, Z. Q.; Chen, C. H.; Cheah, K. W.; Yao, B.; Xie, Z.; Wang, Q.; Ma, D.; Wang, L.; Yu, X. M.; Kwok, H. S.; Lin, Z. Adv. Funct. Mater. 2008, 18, 319. doi: 10.1002/ adfm. 200700665

(11) Chao, Y. C.; Huang, S. Y.; Chen, C. Y.; Chang, Y. F.; Meng, H. F.; Yen, F. W.; Lin, I. F.; Zan, H. W.; Horng, S. F. Synthetic Metals 2011, 161, 148. doi: 10.1016/j.synthmet.2010.11.013

(12) Chuang, T. H.; Yang, C. H.; Kao, P. C. Inorg. Chim. Acta 2009, 362, 5017. doi: 10.1016/j.ica.2009.08.002

(13) Ding, J. Q.; Gao, J.; Fu, Q.; Cheng, Y. X.; Ma, D. G.; Wang, L. X. Synthetic Metals 2005, 155, 539. doi: 10.1016/j.synthmet. 2005.08.034

(14) Song, M.; Park, J. S.; Kim, C. H.; Im, M. J.; Kim, J. S.; Gal, Y. S.; Lee, J. W.; Jin, S. H. Organic Electronics 2009, 10, 1412. doi: 10.1016/j.orgel.2009.07.012

(15) Li, C. X.; Sun, P. P.; Yan, L. J.; Pan, Y.; Cheng, C. J. Thin Solid Films 2008, 516, 6186. doi: 10.1016/j.tsf.2007.11.094

(16) Li, H. C.; Chou, P. T.; Hu, Y. H.; Cheng, Y. M.; Liu, R. S. Organometallics 2005, 24, 1329. doi: 10.1021/om049192n

(17) Rayabarapu, D. K.; Paulose, B. M. J. S.; Duan, J. P.; Chen, C. H. Adv. Mater. 2005, 17, 349. doi: 10.1002/adma.200400813

(18) Shao, Y.; Qiu, Y. Advance Display 1998, 16, 32. [邵 炎, 邱勇. 现代显示, 1998, 16, 32.]

(19) You, X. Z. Molecular Materials-optical Function Compounds; Shanghai Science and Technology Press: Shanghai, 2001. [游 效曾. 分子材料-光电功能化合物. 上海: 上海科学技术出版 社, 2001.]

(20) Danel, A.; Gondek, E.; Kityk, I. V. Opt. Mater. 2009, 32, 267. doi: 10.1016/j.optmat.2009.09.008

(21) Pan, T.; Ning, J. H.; Cai, H. G. Fine Chemical Intermediates 2009, 39, 50. [潘 剘, 宁静恒, 蔡红革. 精细化工中间体, 2009, 39, 50.]

(22) Wu, Q. H.; Wang, C. H.; Song, X. M.; Wu, S. Y.; Jiang, Y. C.; Zhang, G. L. Chin. J. Appl. Chem. 2009, 26,863. [吴秋华, 王 传红, 宋溪明, 吴抒遥, 姜玉春, 张国林. 应用化学, 2009, 26, 863.]

(23) Zhang, G. L.; Guo, H. Q.; Chuo, Y. T.; Zou, D. C. Acta Chim. Sin. 2005, 63, 143. [张国林, 郭海清, 啜玉涛, 邹德春. 化学学 报, 2005, 63, 143.]
(24) Schneidenbach, D.; Ammermann, S.; Debeaux, M.; Freund, A.; Zöllner, M.; Daniliuc, C.; Jones, P. G.; Kowalsky, W.; Johannes, H. H. Inorg. Chem. 2010, 49, 397. doi: 10.1021/ic9009898

(25) Ha, Y.; Seo, J. H.; Kim, Y. K. Synthetic Metals 2008, 158, 548. doi: 10.1016/j.synthmet.2008.03.019

(26) Wu, Q. H.; Wang, C. H.; Song, X. M.; Wu, S. Y.; Zhang, G. L. Chemical Regent 2011, 33, 111. [吴秋华, 王传红, 宋溪明, 吴 抒遥, 张国林. 化学试剂, 2011, 33, 111.]

(27) Duan, J. P.; Sun, P. P.; Cheng, C. H. Adv. Mater. 2003, 15, 224. doi: 10.1002/adma.200390051

(28) Berard, N.; Paventi, M.; Chan, K. P.; Hay, A. S. Macromol. Symp. 1994, 77, 379. doi: 10.1002/masy.19940770139

(29) Hay, A. S. Polymers Derived from Phenolphthaleins. US Patent 5254663, 1993.

(30) Mei, Q. B.;Wang, L. X.; Huang, W.; Tong, B. H.; Guo, Y. H.; Weng, J. N. Synthesis of Iridium Complexes Phosphorescent Material Containing Phthalazine Derivatives as Ligands. CN Patent CN102180909A, 2011-09-14. [梅群波, 王玲霞, 黄 维, 童碧海, 郭远辉, 翁洁娜. 以酞嗪衍生物为配体的铱配 合物磷光材料及其制备方法: 中国, CN102180909A[P]. 2011-09-14.]

(31) Tong, B. H.; Mei, Q. B.; Wang, S. J.; Fang, Y.; Meng, Y. Z.; Wang, B. J. Mater. Chem. 2008, 18, 1636. doi: 10.1039/ b800977e

(32) Mei, Q. B.; Zhang, Q. F.; Tong, B. H. Chin. J. Inorg. Chem. 2009, 25, 264. [梅群波, 张千峰, 童碧海. 无机化学学报, 2009, 25, 264.]

(33) Mi, B. X.; Wang, P. F.; Gao, Z. Q.; Lee, C. S.; Lee, S. T.; Hong, H. L.; Chen, X. M.; Wong, M. S.; Xia, P. F.; Cheah, K. W.; Chen, C. H.; Huang, W. Adv. Mater. 2009, 21, 339. doi: 10.1002/ adma.200801604

(34) Fang, Y.; Tong, B. H.; Hu, S. J.; Wang, S. J.; Meng, Y. Z.; Peng, J. B.; Wang, B. Organic Electronics 2009, 10, 618. doi: 10.1016/ j.orgel.2009.02.013

(35) Fang, Y.; Hu, S. J.; Meng, Y. Z.; Peng, J. B.; Wang, B. Inorg Chim. Acta 2009, 362, 4985. doi: 10.1016/j.ica.2009.08.007

(36) Fang, Y.; Li, Y. H.; Wang, S. J.; Meng, T. Z.; Peng, J. B.; Wang, B. Synthetic Metals 2010, 160, 2231. doi: 10.1016/j.synthmet. 2010.07.035

(37) Lee, J. Y.; Park, Y. K.; Seo, S. H.; So, I. S.; Chung, H. K.; Yang, B. S.; Lee, S. J.; Park, H.; Lee, Y. S. Arch. Pharm. Pharm. Med. Chem. 2001, 334, 357. doi: 10.1002/1521-4184(200112)334:11< 357::AID-ARDP357>3.0.CO;2-Q

(38) Wissner, A.; Overbeek, E.; Reich, M. F.; Floyd, M. B.; Johnson, B. D.; Mamuya, N.; Rosfjord, E. C.; Discafani, C.; Davis, R.; Shi, X. Q.; Rabindran, S. K.; Gruber, B. C.; Ye, F.; Hallett, W. A.; Nilakantan, R.; Shen, R.; Wang, Y. F.; Greenberger, L. M.; Tsou, H. R. J. Med. Chem. 2003, 46, 49. doi: 10.1021/ jm020241c

(39) Xu, G. F.; Song, B. A.; Bhadury, P. S.; Yang, S.; Zhang, P. Q.; Jin, L. H.; Xue, W.; Hu, D. Y.; Lu, P. Bioorg. Med. Chem. 2007, 
15, 3768. doi: 10.1016/j.bmc.2007.03.037

(40) Song, Y. H.; Yeh, S. J.; Chen, C. T.; Chi, Y.; Liu, C. S.; Yu, J. K.; Hu, Y. H.; Chou, P. T.; Peng, S. M.; Lee, G. H. Adv. Funct. Mater. 2004, 14, 1221. doi: 10.1002/adfm.200400137

(41) Du, B. S.; Lin, C. H.; Chi, Y.; Hung, J. Y.; Chung, M. W.; Lin, T. Y.; Lee, G. H.; Wong, K. T.; Chou, P. T.; Hung, W. Y.; Chiu, H. C. Inorg. Chem. 2010, 49, 8713. doi: 10.1021/ic100935b

(42) Zhang, Y. X.; Du, H. M.; Hu, L. F.; Li, H. Y.; Sun, J.; Zhang, C. L.; Zhang, H. K.; Zhang, G. X.; Gao, R. X. Red Organic Electroluminescent Phosphorescent Iridium Complex Containing Aryl Linked Quinazoline Derivatives as Ligands and the Light-emitting Diodes. CN Patent CN101899296, 2010-1201. [张玉祥, 杜红梅, 胡灵峰, 李红燕, 孙 军, 张春林, 张弘 科, 张国选, 高仁孝. 含芳基联喹唑啉类金属铱配合物红色有 机电致磷光材料及其有机电致发光器件. 中国, CN101899296 [P]. 2010-12-01.]

(43) Hsu, N. M.; Li, W. R. Angew. Chem. 2006, 45, 4138. doi: 10.1002/anie.200600004

(44) Mei, Q. B.; Wang, L. X.; Guo, Y. H.; Weng, J. N.; Yan, F.; Tian, B.; Tong, B. H. J. Mater. Chem. 2012, 22, 6878. doi: 10.1039/ c2jm15160j

(45) Horton, D. A.; Bourne, G. T.; Smythe, M. L. Chem. Rev. 2003, 103, 893. doi: 10.1021/cr020033s

(46) Leng, W. N.; Zhou, Y. M.; Xu, Q. H.; Liu, J. Z. Polymer 2001, 42, 9253. doi: 10.1016/S0032-3861(01)00464-5

(47) Mori, A.; Sekiguchi, A.; Masui, K.; Shimada, T.; Horie, M.; Osakada, K.; Kawamoto, M.; Ikeda, T. J. Am. Chem. Soc. 2003, 125, 1700. doi: 10.1021/ja0289189

(48) Becker, R. S.; Lenolele, C.; Zein, A. J. Phys. Chem. 1987, 91, 3509. doi: 10.1021/j100297a011

(49) Laskar, I. R.; Chen, T. M. Chem. Mater. 2004, 16, 111. doi: 10.1021/cm030410x

(50) Brooks, J.; Babayan, Y.; Lamansky, S.; Djurovich, P. I.; Tsyba, I.; Bau, R.; Thompson, M. E. Inorg. Chem. 2002, 41, 3055. doi: 10.1021/ic0255508

(51) Lamansky, S.; Djurovich, P.; Murphy, D.; Abdel-Razaq, F.; Lee, H. E.; Adachi, C.; Burrows, P. E.; Forrest, S. R.; Thompson, M. E. J. Am. Chem. Soc. 2001, 123, 4304. doi: 10.1021/ja003693s

(52) Tabbe, M. J.; Spitzer, W. A.; Victor, F.; Mikker, S. C.; Lee, C. C.; Sattelberg, T. R.; McKinnet, E.; Tang, J. C. J. Med. Chem. 1997, 40, 3937. doi: 10.1021/jm970423k

(53) Huang, W. S.; Lin, J. T.; Chien, C. H.; Tao, Y. T.; Sun, S. S.; Wen, Y. S. Chem. Mater. 2004, 16, 2480. doi: 10.1021/ cm0498943

(54) Ruan, J. W.; Fu, L. W.; Huang, Z. S. Chem. J. Chin. Univ. 2004, 25, 870. [阮继武, 符立梧, 黄志纾. 高等学校化学学报,
2004, 25, 870.]

(55) Anthopoulos, T. D.; Frampton, M. J.; Namdas, E. B.; Burn, P. L.; Samuel, I. D. W. Adv. Mater. 2004, 16, 557. doi: 10.1002/ adma.200306095

(56) Frampton, M. J.; Namdas, E. B.; Lo, S. C.; Bun, P. L.; Samuel, I. D. W. J. Mater. Chem. 2004, 14, 2881. doi: 10.1039/b400160e

(57) Malinauskas, T.; Daskeviciene, M.; Kazlauskas, K.; Su, H. C.; Grazulevicius, J. V.; Jursenas, S.; Wu, C. C.; Getautis, V. Tetrahedron 2011, 67, 1852. doi: 10.1016/j.tet.2011.01.026

(58) Li, X. H.; Zhao, X. D.; Lü, K. L.; Zhang, A. Q. Chin. J. Inorg. Chem. 2011, 27, 303. [李襄宏, 赵金帝, 吕康乐, 张爱清. 无机 化学学报, 2011, 27, 303.]

(59) Zhou, G. J.; Wong, W. Y.; Yao, B.; Xie, Z.; Wang, L. Angew. Chem. Int. Edit. 2007, 46, 1194.

(60) Ding, J. Q.; Lü, J. H.; Cheng, Y. X.; Xie, Z. Y.; Wang, L. X.; Jing, X. B.; Wang, F. S. Adv. Funct. Mater. 2008, 18, 2754. doi: 10.1002/adfm.200800259

(61) Guo, Y. H.; Wang, L. X.; Weng, J. N.; Yan, F.; Mei, Q. B.; Huang, W. Chin. Sci. Bull. 2011, 56, 2548. [ 郭远辉, 王玲霞, 翁洁娜, 颜 芳, 梅群波, 黄 维. 科学通报, 2011, 56, 2548.] doi: 10.1360/972011-91

(62) Sandee, A. J.; Williams, C. K.; Evans, N. R.; Davies, J. E.; Boothby, C. E. J. Am. Chem. Soc. 2004, 126, 7041. doi: 10.1021/ ja039445o

(63) Zhang, K.; Chen, Z.; Yang, C. L.; Gong, S. L.; Qin, J. G.; Cao, Y. Macromol. Rapid Commun. 2006, 27, 1926. doi: 10.1002/ marc. 200600525

(64) Liu, S. J.; Zhao, Q.; Chen, R. F.; Deng, Y.; Fan, Q. L.; Li, F. Y.; Wang, L. H.; Huang, C. H.; Huang, W. Chem. Eur. J. 2006, 12, 4351. doi: 10.1002/chem.200501095

(65) Liu, S. J.; Zhao, Q.; Deng, Y.; Xia, Y. J.; Lian, J.; Fan, Q. L.; Wang, L. H.; Huang, W. J. Phys. Chem. C 2007, 111, 1166. doi: 10.1021/jp064819w

(66) Tokito, S.; Suzuki, M.; Sato, F.; Kamachi, M.; Shirane, K. Organic Electronics 2003, 4, 105. doi: 10.1016/j.orgel. 2003.08.005

(67) Jiang, J. X.; Jiang, C. Y.; Yang, W.; Zhen, H. Y.; Huang, F.; Cao, Y. Macromolecules 2005, 38, 4072. doi: 10.1021/ma0474473

(68) Yang, X. H.; Wu, F. L.; Neher, D.; Chien, C. H.; Shu, C. F. Chem. Mater. 2008, 20, 1629. doi: 10.1021/cm702789c

(69) Deng, J. Y.; Liu, Y.; Wang, Y. F.; Tan, H.; Zhang, Z. Y.; Lei, G. T.; Yu, J. T.; Zhu, M. X.; Zhu, W. G.; Cao, Y. European Polymer Journal 2011, 47, 1836. doi: 10.1016/j.eurpolymj.2011.06.015

(70) Tan, H.; Yu, J. T.; Nie, K. X.; Chen, J. H.; Deng, X. P.; Zhang, Z. Y.; Lei, G. T.; Zhu, M. X.; Liu, Y.; Zhu, W. G. Polymer 2011, 52, 4792. doi: 10.1016/j.polymer.2011.07.058 